\title{
Preoperative carbohydrate load and intraoperatively infused omega-3 polyunsaturated fatty acids positively impact nosocomial morbidity after coronary artery bypass grafting: a double- blind controlled randomized trial
}

Gibran Roder Feguri ${ }^{1,2,3,8^{*}}$, Paulo Ruiz Lúcio de Lima ${ }^{4}$, Danilo de Cerqueira Borges², Laura Ramos Toledo ${ }^{5}$, Larissa Nadaf Batista ${ }^{2}$, Thaís Carvalho e Silva ${ }^{2}$, Neuber José Segri ${ }^{6}$ and José Eduardo de Aguilar-Nascimento ${ }^{7}$

\begin{abstract}
Background: A strategy of limited preoperative fasting, with carbohydrate $(\mathrm{CHO})$ loading and intraoperative infusion of omega-3 polyunsaturated fatty acids ( $\omega-3$ PUFA), has seldom been tried in cardiovascular surgery. Brief fasting, followed by $\mathrm{CHO}$ intake $2 \mathrm{~h}$ before anesthesia, may improve recovery from CABG procedures and lower perioperative vasoactive drug requirements. Infusion of $\omega$-3 PUFA may reduce occurrences of postoperative atrial fibrillation (POAF) and shorten hospital stays. The aim of this study was to assess morbidity (especially POAF) in ICU patients after coronary artery bypass grafting (CABG)/cardiopulmonary bypass (CPB) in combination, if preoperative fasts are curtailed in favor of $\mathrm{CHO}$ loading, and $\omega-3$ PUFA are infused intraoperatively.

Methods: Fifty-seven patients undergoing CABG were randomly assigned to receive $12.5 \%$ maltodextrin (200 ml, $2 \mathrm{~h}$ before anesthesia), without infusing $\omega-3$ PUFA $(\mathrm{CHO}, n=14)$; water $(200 \mathrm{ml}, 2 \mathrm{~h}$ before anesthesia), without infusing $\omega-3$ PUFA (controls, $n=14) ; 12.5 \%$ maltodextrin $(200 \mathrm{ml}, 2 \mathrm{~h}$ before anesthesia) plus intraoperative $\omega-3$ PUFA $(0.2 \mathrm{mcg} / \mathrm{kg})(\mathrm{CHO}+\mathrm{W} 3, n=15)$; or water $(200 \mathrm{ml}, 2 \mathrm{~h}$ before anesthesia) plus intraoperative $\omega-3$ PUFA $(0.2$ $\mathrm{mcg} / \mathrm{kg})(\mathrm{W} 3, n=14)$. Perioperative clinical variables and mortality were analyzed, examining the incidence of POAF, as well as the need for inotropic vasoactive drugs during surgery and in ICU.

Results: Two deaths occurred (3.5\%), but there were no instances of bronchoaspiration and mediastinitis. Neither ICU stays nor total postoperative stays differed by group $(P>0.05)$. Patients given preoperative $\mathrm{CHO}$ loads ( $\mathrm{CHO}$ and $\mathrm{CHO}+\mathrm{W} 3$ groups) experienced fewer instances of hospital infection $(\mathrm{RR}=0.29,95 \% \mathrm{Cl} 0.09-0.94 ; \mathrm{P}=0.023)$ and were less reliant on vasoactive amines during surgery ( $R R=0.60,95 \% \mathrm{Cl} 0.38-0.94 ; P=0.020)$. Similarly, the number of patients requiring vasoactive drugs while recovering in ICU differed significantly by group $(P=0.008)$, showing benefits in patients given $\mathrm{CHO}$ loads. The overall incidence of POAF was $29.8 \%(17 / 57)$, differing significantly by group $(P=0.009)$. Groups given $\omega-3$ PUFA (W3 and $\mathrm{CHO}+$ W3 groups) experienced significantly fewer instances of $\mathrm{POAF}(\mathrm{RR}=4.83,95 \% \mathrm{Cl} 1.56-15.02 ; P=0.001)$.

(Continued on next page)
\end{abstract}

\footnotetext{
* Correspondence: gibranrf@yahoo.com.br

${ }^{1}$ Federal University of Mato Grosso, Cuiabá, Brazil

${ }^{2}$ General University Hospital, Cuiabá, Brazil

Full list of author information is available at the end of the article
} 
(Continued from previous page)

Conclusion: Preoperative curtailment of fasting was safe in this cohort. When implemented in conjunction with $\mathrm{CHO}$ loading and infusion of $\omega-3$ PUFA during surgery, expedited recovery from CABG with CPB was observed.

Trial registration: NCT: 03017001

Keywords: Myocardial revascularization, CAGB, Perioperative care, POAF, Fasting, Metabolism

\section{Background}

Omega-3 polyunsaturated fatty acids ( $\omega-3$ PUFA) are likely involved in proper balance of host immunity postoperatively. Although most studies of nutrients implicated in immunity pertain to abdominal surgery, there is some evidence that $\omega-3$ PUFA is beneficial for patients undergoing cardiac surgery as well [1]. A recent metaanalysis has shown that $\omega-3$ PUFA may reduce the incidence of postoperative atrial fibrillation (POAF) and shorten hospital stays [2, 3].

POAF is among the most common complications after coronary artery bypass grafting (CABG), ranging from 10 to $40 \%$ in incidence. Such events are known to impact healthcare costs, morbidity and mortality, postoperative discomfort, and tachycardia, necessitating rhythm reversal and prolonging ICU stays or forcing readmission. Hence, perioperative strategies to minimize occurrences of POAF are of great importance and are constantly under study $[4,5]$.

On the other hand, an abbreviated period of preoperative fasting with oral intake of carbohydrate $(\mathrm{CHO})$ may offset insulin resistance after surgery and help reduce postoperative nausea and vomiting (PONV) [6]. In cardiac surgery specifically, some randomized trials have shown that $\mathrm{CHO}$ loading $2 \mathrm{~h}$ before inducing anesthesia will reduce ICU and hospital stays while reducing the need for perioperative vasoactive drug delivery $[7,8]$.

In our search of the current literature, no studies to date have combined preoperative $\mathrm{CHO}$ loading and intraoperative infusion of $\omega-3$ PUFA in cardiac surgery. Presuming that this combination might confer some benefit, this study was conducted to investigate the effects of these two nutrients on morbidity in ICU (POAF primarily) suffered by patients who undergo CABG with cardiopulmonary bypass $(\mathrm{CPB})$.

\section{Methods}

This was a double-blind, controlled and randomized trial, examining patients subjected to CABG with $\mathrm{CPB}$ at General University Hospital, Cuiabá, Brazil between March, 2014 and June, 2016. The hospital's Ethics Committee granted approval in advance (Protocol No 30493514.5.000.5165; 2014), and a Clinical Trials registration (NCT: 03017001) was obtained.

Patients of both genders (age range, 18-80 years) were included, each medically diagnosed with chronic coronary heart disease and eligible for elective CABG. All patients granted written informed consent. Grounds for exclusion were insulin-dependent diabetes, hepatic or renal disorders, thrombocytopenia, critical dyslipidemia (triglycerides 3-fold greater than established normal), gastroesophageal reflux, acute coronary syndromes, allergy to fish oil, and severe malnutrition. Candidates undergoing off-pump CABG, combined heart procedures, reoperations, or blood transfusion within 3 months prior were also excluded.

Using standard software (QuickCalcs [online]; GraphPad Software Inc, San Diego, CA, USA), subjects were randomly assigned to one of four groups as follows: 1 ) CHO (8-h fast for solids; 2 -h fast plus 200-mL oral intake of $12.5 \%$ maltodextrin $[25 \mathrm{~g}]$ in water; no intraoperative $\omega$-3 PUFA); 2) controls (8-fast for solids; 2-h fast plus 200-mL oral intake of water only; no intraoperative $\omega$-3 PUFA); 3) CHO + W3 (8-h fast for solids; 2-h fast plus $200-\mathrm{mL}$ oral intake of $12.5 \%$ maltodextrin $[25 \mathrm{~g}]$ in water; intraoperative infusion of $\omega-3$ PUFA $[0.2 \mathrm{mcg} / \mathrm{kg}$ over $4 \mathrm{~h}$ )); and 4) W3 (8-fast for solids; 2-h fast plus 200-mL oral intake of water only; intraoperative infusion of $\omega-3$ PUFA [0.2 mcg $/ \mathrm{kg}$ over $4 \mathrm{~h}]$ ).

A hospital dietitian, as sole attendant privy to charted randomization, directed preoperative intake. Drinks delivered by ward nurse were given to patients before transport to the operative suite. The anesthesiologist was also informed (by dietician) of which patients would receive intraoperative $\omega-3$ PUFA. None of the surgical team (surgeon or assistants) was aware of patient assignments. A team of cardiologists and intensive care physicians, also blind to study design and patient randomization, collected all data.

\section{Endpoints}

Primary study endpoints were incidence of POAF and need of inotropic vasoactive drugs (dobutamine and/or noradrenalin) for weaning from CPB intraoperatively or postoperatively in ICU. As secondary endpoints, perioperative morbidity, hospital mortality, and durations of ICU and total postoperative hospitalization were analyzed.

\section{Anesthesia and surgical technique}

The same surgeon (GRF) performed all procedures. Routine anesthetic techniques were used, namely induction via infusion of etomidate $(0.2 \mathrm{mg} / \mathrm{kg})$, fentanyl citrate $(5 \mathrm{mcg} /$ $\mathrm{kg})$, and pancuronium bromide $(0.1 \mathrm{mg} / \mathrm{kg})$. Isoflurane was administered by inhalation route in usual doses (0.6-1.8\%) until end of procedure for balanced general anesthesia. As 
maintenance, another bolus of fentanyl ( $2 \mathrm{mcg} / \mathrm{kg})$, midazolam $(0.1 \mathrm{mg} / \mathrm{kg})$, and pancuronium bromide $(0.05 \mathrm{mg} / \mathrm{kg})$ was given, serving for muscle relaxation. All patients were kept under mechanical ventilation, with oxygen (FiO2) at $60 \%$ (or higher if needed).

Surgical entry was through median sternotomy, with $\mathrm{CPB}$ in the allotted time. The oxygenator used was membrane type (Braile Biomédica, São José do Rio Preto, Brazil). To protect myocardium, we used hypothermic intermittent anterograde blood cardioplegia (every 15$20 \mathrm{~min}$ ), along with mild systemic hypothermia $\left(33^{\circ}-35^{\circ}\right.$ C). All patients received intravenous cefuroxime $(1.5 \mathrm{~g})$ $1 \mathrm{~h}$ before inducing anesthesia, giving another dose after $\mathrm{CPB}$. Maintenance doses $(750 \mathrm{mg})$ were then administered every $6 \mathrm{~h}$ for $48 \mathrm{~h}$. A bolus of methyl prednisolone $(7 \mathrm{mg} /$ $\mathrm{kg}$ ) was delivered intravenously at anesthesia induction.

\section{Statistical analysis}

The calculation of the sample size was based on the premise that the intervention with $\mathrm{W} 3+\mathrm{CHO}$ protocol would reduce POAF by $50 \%$ versus controls. Assuming a $\beta$ error (type II) of $20 \%$ and a $\alpha$ error (type I) of $5 \%$, sample size calculations indicated 15 patients per group would be sufficient for this study. For values with Gaussian distributions, we used parametric paired (or non-paired) t-tests and analysis of variance for repeated measures, applying nonparametric tests (Friedman, Wilcoxon, and MannWhitney) to values with non-Gaussian distributions. Qualitative variables were assessed via chi-square and Fisher's exact tests. Descriptive analyses were undertaken in Microsoft Office Excel 2007 (Microsoft Corp, Redmond, WA, USA), and statistical computations relied on SPSS v17.0 (SPSS Inc, Chicago, IL, USA). All testing was two-tailed at $80 \%$ power, with significance set at $P<0.05$.

\section{Results}

A study flowchart is depicted in Fig. 1. Although 96 patients were eligible, 36 were excluded for various reasons. Ultimately, 60 were randomly assigned to the four groups; and after excluding one patient each from groups $\mathrm{CHO}$, W3, and controls, 57 remained for analysis $(\mathrm{CHO}+\mathrm{W} 3: n$ $=15$; others: $n=14$, each). Nutritional and demographic data are shown by group in Table 1 . In Table 2, clinical data of all groups are presented. All comparisons of the above showed these groups to be homogeneous.

\section{Intraoperative period}

No patients suffered bronchial aspiration during intubation or after terminating anesthesia, and no intraoperative deaths occurred. Data from the intraoperative period are shown Table 3. There were no significant differences among the four groups.

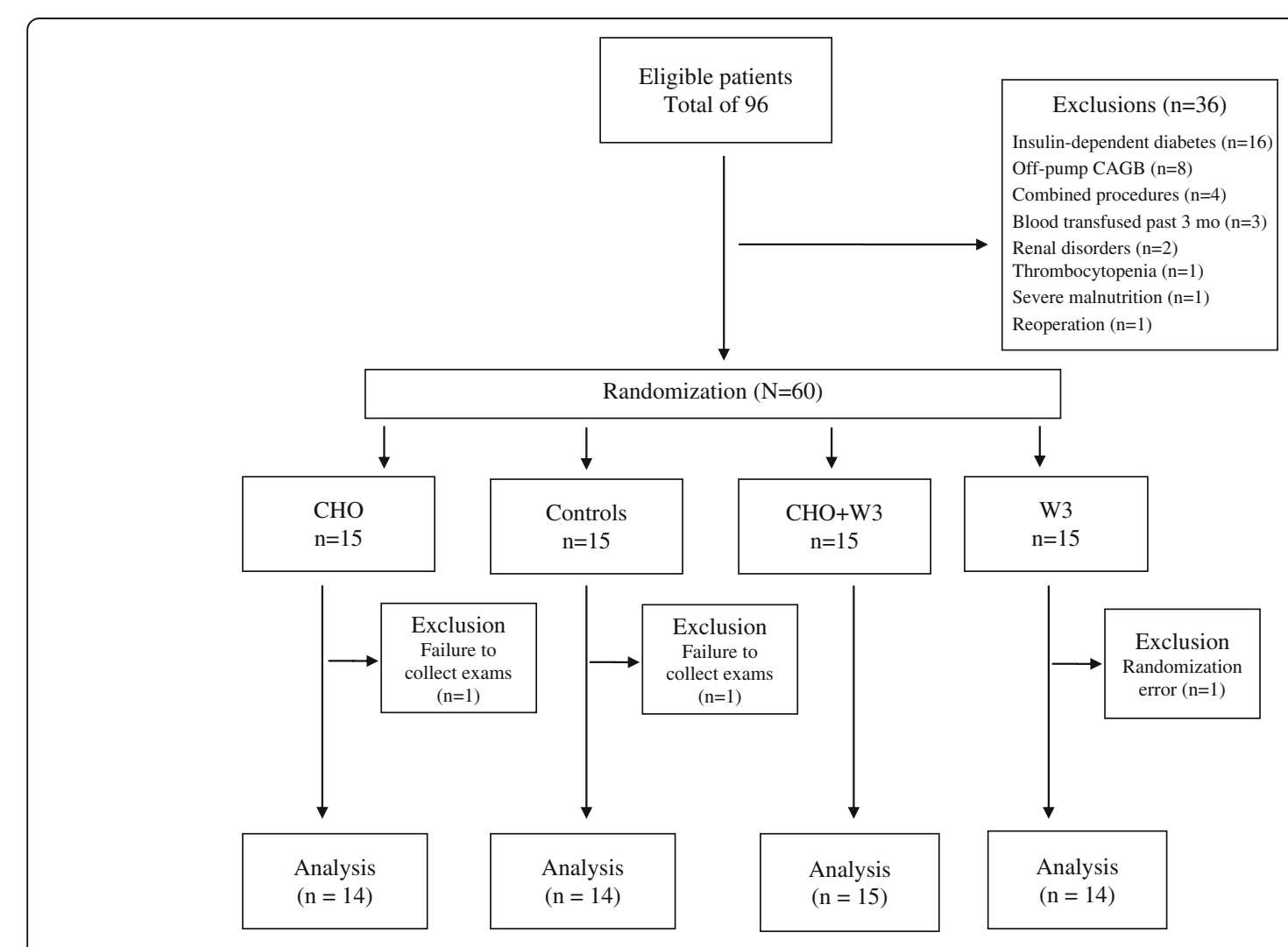

Fig. 1 Flowchart of study design 
Table 1 Demographic, nutritional, and clinical data of patient population $(N=57)$ by group

\begin{tabular}{|c|c|c|c|c|c|}
\hline & $\begin{array}{l}\mathrm{CHO} \\
(n=14)\end{array}$ & $\begin{array}{l}\text { Control } \\
(n=14)\end{array}$ & $\begin{array}{l}\mathrm{CHO}+\mathrm{W} 3 \\
(n=15)\end{array}$ & $\begin{array}{l}\text { W3 } \\
(n=14)\end{array}$ & $P$ value \\
\hline Age (y/o) & $\begin{array}{l}60.86 \pm 10.55 \\
(63.00)\end{array}$ & $\begin{array}{l}63.43 \pm 8.56 \\
(63.50)\end{array}$ & $\begin{array}{l}59.93 \pm 11.77 \\
(63.00)\end{array}$ & $\begin{array}{l}62.71 \pm 10.90 \\
(65.00)\end{array}$ & $0.797^{a}$ \\
\hline Males & $12(86)$ & $10(71)$ & $7(47)$ & $9(64)$ & $0.160^{c}$ \\
\hline Caucasians & $7(50)$ & $9(64)$ & $8(53)$ & $5(36)$ & $0.380^{c}$ \\
\hline Body weight (kg) & $\begin{array}{l}72.71 \pm 12.58 \\
(71,90)\end{array}$ & $\begin{array}{l}72.82 \pm 11.21 \\
(71.20)\end{array}$ & $\begin{array}{l}65.95 \pm 10.69 \\
(66.00)\end{array}$ & $\begin{array}{l}73.78 \pm 18.66 \\
(69.20)\end{array}$ & $0.513^{b}$ \\
\hline Height (m) & $\begin{array}{l}1.67 \pm 0.10 \\
(1.64)\end{array}$ & $\begin{array}{l}1.63 \pm 0.08 \\
(1.62)\end{array}$ & $\begin{array}{l}1.64 \pm 0.07 \\
(1.64)\end{array}$ & $\begin{array}{l}1.64 \pm 0.10 \\
(1.64)\end{array}$ & $0.663^{a}$ \\
\hline BMI $\left(\mathrm{kg} / \mathrm{m}^{2}\right)$ & $\begin{array}{l}26.26 \pm 3.59 \\
(26.60)\end{array}$ & $\begin{array}{l}26.49 \pm 3.38 \\
(26.30)\end{array}$ & $\begin{array}{l}25.27 \pm 3.48 \\
(25.40)\end{array}$ & $\begin{array}{l}27.26 \pm 5.64 \\
(25.70)\end{array}$ & $0.911^{b}$ \\
\hline SGA-A (n; \%) & $11(79)$ & $13(93)$ & $13(87)$ & $13(93)$ & $0.617^{c}$ \\
\hline
\end{tabular}

Data expressed as mean $\pm \mathrm{SD}$, median (in parentheses) for continuous variables, or number (\%) for categorical variables $B M I$ body mass index, SGA subjective global assessment

ane way-ANOVA

${ }^{\mathrm{b}}$ Kruskal-Wallis test

${ }^{c}$ Chi-square test

The number of patients needing vasoactive drugs (dobutamine and/or noradrenaline) for weaning from $\mathrm{CPB}$ did not differ significantly by group (CHO: 7/14, 50.0\%; controls: 12/14, 85.7\%; $\mathrm{CHO}+\mathrm{W} 3:$ 6/15, 40.0\%; W3: $9 /$ $14,64.3 \%)$, although a tendency for control subjects to require such agents was noted $(P=0.071)$. Relative to other group members (W3 and control groups), patients given preoperative $\mathrm{CHO}$ loads $(\mathrm{CHO}$ and $\mathrm{CHO}+\mathrm{W} 3$ groups) were less apt to require vasoactive amines $(\mathrm{RR}=$ $0.60,95 \%$ CI $0.38-0.94 ; P=0.020$ ).

\section{Postoperative period}

Clinical data from the postoperative period are shown in Table 4 . ICU stays did not differ significantly by group $(P=0.713)$. Group means (medians) $\pm \mathrm{SD}$ were as follows: $\mathrm{CHO}, 2.86$ (2) \pm 1.88 days; controls, 3.43 (2) \pm
3.16 days; $\mathrm{CHO}+\mathrm{W} 3,2.80$ (3) \pm 0.94 days; and $\mathrm{W} 3,3.36$ (3) \pm 1.55 days. Likewise, total postoperative stays did not differ significantly by group $(P=0.998)$. Group mean \pm SD were as follows: $\mathrm{CHO}, 8.42 \pm 7.79$ days; controls, $8.07 \pm 4.5$ days; $\mathrm{CHO}+\mathrm{W} 3,7.00 \pm 1.51$ days; and $\mathrm{W} 3$, $7.50 \pm 2.77$ days.

The number of patients needing vasoactive drugs (dobutamine and/or noradrenaline) during recovery in ICU did differ significantly by group $(\mathrm{CHO}, 3 / 14 ; 21.4 \%$; controls, 10/14; 71.4\%; $\mathrm{CHO}+\mathrm{W} 3,3 / 15 ; 20.0 \%$; and W3, 8/14; $57.1 \%)(P=0.008)$. Notable differences were evident in both groups given preoperative $\mathrm{CHO}$ loads, compared with controls. No other calculations reached significance.

The overall incidence of POAF was 29.8\% (17/57). However, rates differed significantly by group $(P=0.009)$. Those given $\omega-3$ PUFA (W3 and $\mathrm{CHO}+\mathrm{W} 3$ groups)

Table 2 Clinical data and risk factors of patient population $(N=57)$ by group

\begin{tabular}{|c|c|c|c|c|c|}
\hline & $\mathrm{CHO}$ & Control & $\mathrm{CHO}+\mathrm{W} 3$ & W3 & $P$ value \\
\hline & $(n=14)$ & $(n=14)$ & $(n=15)$ & $(n=14)$ & \\
\hline LVEF & $\begin{array}{l}0.55 \pm 0.12 \\
(0.60)\end{array}$ & $\begin{array}{l}0.57 \pm 0.11 \\
(0.60)\end{array}$ & $\begin{array}{l}0.54 \pm 0.13 \\
(0.60)\end{array}$ & $\begin{array}{l}0.62 \pm 0.11 \\
(0.65)\end{array}$ & $0.168^{a}$ \\
\hline Smoking & $6(43)$ & $9(64)$ & $7(47)$ & $8(57)$ & $0.653^{b}$ \\
\hline Diabetes & $4(29)$ & $3(21)$ & $5(33)$ & $6(43)$ & $0.666^{b}$ \\
\hline Dyslipidemia & $11(79)$ & $12(86)$ & $8(53)$ & $11(79)$ & $0.204^{b}$ \\
\hline Previous AMI & $7(50)$ & $9(64)$ & $6(40)$ & $7(50)$ & $0.631^{b}$ \\
\hline Beta-blocker use & $9(64)$ & $10(71)$ & $6(40)$ & $11(79)$ & $0.151^{b}$ \\
\hline Statin use & $11(79)$ & $11(79)$ & $9(60)$ & $11(79)$ & $0.580^{b}$ \\
\hline Fibrate use & $2(14)$ & $2(14)$ & $2(13)$ & $3(21)$ & $0.930^{b}$ \\
\hline Previous PCl & $1(7)$ & $4(29)$ & $4(27)$ & $3(21)$ & $0.495^{b}$ \\
\hline
\end{tabular}

Data expressed as mean $\pm S D$, median (in parentheses) for continuous variables, or number (\%) for categorical variables

$L V E F$ left ventricular ejection fraction, $A M I$ acute myocardial infarction, $P C l$ percutaneous coronary intervention

${ }^{a}$ Kruskal-Wallis test

${ }^{\mathrm{b}}$ Chi-square test 
Table 3 Intraoperative patient data $(N=57)$ by group

\begin{tabular}{|c|c|c|c|c|c|}
\hline & $\begin{array}{l}\mathrm{CHO} \\
(n=14)\end{array}$ & $\begin{array}{l}\text { Control } \\
(n=14)\end{array}$ & $\begin{array}{l}\mathrm{CHO}+\mathrm{W} 3 \\
(n=15)\end{array}$ & $\begin{array}{l}\text { W3 } \\
(n=14)\end{array}$ & $P$ value \\
\hline Operative time (min) & $\begin{array}{l}244.64 \pm 40.31 \\
(240.00)\end{array}$ & $\begin{array}{l}232.31 \pm 49.27 \\
(225.00)\end{array}$ & $\begin{array}{l}249.29 \pm 24.01 \\
(240.00)\end{array}$ & $\begin{array}{l}253.93 \pm 40.86 \\
(270.00)\end{array}$ & $0.532^{\mathrm{a}}$ \\
\hline Duration of CPB (min) & $\begin{array}{l}77.14 \pm 20.37 \\
(82.50)\end{array}$ & $\begin{array}{l}66.64 \pm 24.50 \\
(60.00)\end{array}$ & $\begin{array}{l}63.53 \pm 15.63 \\
(66.00)\end{array}$ & $\begin{array}{l}78.79 \pm 22.93 \\
(85.00)\end{array}$ & $0.147^{\mathrm{a}}$ \\
\hline Duration of AC (min) & $\begin{array}{l}63.71 \pm 17.29 \\
(66.50)\end{array}$ & $\begin{array}{l}56.86 \pm 28.21 \\
(50.50)\end{array}$ & $\begin{array}{l}54.20 \pm 15.52 \\
(56.00)\end{array}$ & $\begin{array}{l}61.57 \pm 18.58 \\
(68.00)\end{array}$ & $0.586^{\mathrm{a}}$ \\
\hline Blood components transfused & $7(50)$ & $7(50)$ & $7(47)$ & $8(57)$ & $0.953^{b}$ \\
\hline Number of grafts & $\begin{array}{l}3.00 \pm 0.96 \\
(3.00)\end{array}$ & $\begin{array}{l}2.36 \pm 0.93 \\
(2.00)\end{array}$ & $\begin{array}{l}2.67 \pm 0.82 \\
(3.00)\end{array}$ & $\begin{array}{l}2.86 \pm 0.86 \\
(3.00)\end{array}$ & $0.266^{\mathrm{a}}$ \\
\hline Complications & $1(7)$ & $2(14)$ & $0(0)$ & $1(7)$ & $0.519^{b}$ \\
\hline
\end{tabular}

Data expressed as mean $\pm S D$, median (in parentheses) for continuous variables, or number (\%) for categorical variables

$C P B$ cardiopulmonary bypass, $A C$ aortic clamping

${ }^{\mathrm{a}}$ One-way ANOVA

${ }^{\mathrm{b}}$ Chi-square test

experienced significantly less POAF than controls, and patients given both nutrients $(\mathrm{CHO}+\mathrm{W} 3)$ fared significantly better than those given $\mathrm{CHO}$ only $(P=0.035)$. Members of the $\mathrm{CHO}$ group did not differ significantly from controls $(P=0.571)$. Only 3 patients $(10.3 \%)$ in the W3 and $\mathrm{CHO}+\mathrm{W} 3$ groups developed POAF, compared with 14 $(50.0 \%)$ in the other two groups $(\mathrm{RR}=4.83,95 \% \mathrm{CI} 1.56-$ $15.02 ; P=0.001$ ).

\section{Infectious complications and hospital mortality}

There were no instances of postoperative mediastinitis. Thirteen patients $(22.8 \%)$ experienced postoperative infections, specifically pneumonia ( $n=9$; two with sepsis) and wound site infections $(n=5)$. Although differences among groups approached significance $(P=0.069)$, as seen in Table 4, groups given preoperative $\mathrm{CHO}$ loads ( $\mathrm{CHO}$ and $\mathrm{CHO}+\mathrm{W} 3$ groups) incurred significantly fewer infections than the others $(\mathrm{RR}=0.29,95 \% \mathrm{CI}$ 0.09-0.94; $P=0.023$ ).

Overall, two deaths $(3.5 \%)$ were recorded, one control subject and a member of the W3 group $(P=0.543)$. These occurred during ICU recovery. The control subject was a woman diagnosed with a stroke in the immediate postoperative period. She progressed to acute renal failure (requiring hemodialysis), sepsis, and then cardiogenic and septic shock. The W3 group member was a man diagnosed with perioperative acute myocardial infarction that led to refractory cardiogenic shock and acute renal failure.

\section{Discussion}

In aggregate, these study outcomes indicate that administering preoperative $\mathrm{CHO}$ loads and intraoperative $\omega-3$ PUFA is beneficial in the aftermath of CABG. Not only did fewer patients require vasoactive drugs for weaning

Table 4 Clinical data during postoperative patient recovery $(N=57)$ by group

\begin{tabular}{|c|c|c|c|c|c|}
\hline & $\begin{array}{l}\mathrm{CHO} \\
(n=14)\end{array}$ & $\begin{array}{l}\text { Control } \\
(n=14)\end{array}$ & $\begin{array}{l}\mathrm{CHO}+\mathrm{W} 3 \\
(n=15)\end{array}$ & $\begin{array}{l}\text { W3 } \\
(n=14)\end{array}$ & $P$ value \\
\hline PONV at ICU & $3(21)$ & $4(29)$ & $2(13)$ & $5(36)$ & $0.541^{b}$ \\
\hline Duration of MV (hours) & $\begin{array}{l}10.92 \pm 11.12 \\
(8.25)\end{array}$ & $\begin{array}{l}8.47 \pm 2.62 \\
(8.50)\end{array}$ & $\begin{array}{l}8.96 \pm 4.01 \\
(8.67)\end{array}$ & $\begin{array}{l}8.21 \pm 3.57 \\
(7.50)\end{array}$ & $0.959^{a}$ \\
\hline Blood loss by 12 h PO & $\begin{array}{l}353.57 \pm 355.43 \\
(300.00)\end{array}$ & $\begin{array}{l}204.64 \pm 99.78 \\
(200.00)\end{array}$ & $\begin{array}{l}233.33 \pm 134.52 \\
(200.00)\end{array}$ & $\begin{array}{l}278.57 \pm 169.52 \\
(225.00)\end{array}$ & $0.351^{a}$ \\
\hline Vasoactive drug needed in ICU & $3(21)$ & $10(71)$ & $3(20)$ & $8(57)$ & $0.008^{b}$ \\
\hline Blood components needed in ICU & $6(43)$ & $5(36)$ & $3(20)$ & $3(21)$ & $0.470^{b}$ \\
\hline EVA & $0(0)$ & $2(14)$ & $1(7)$ & $0(0)$ & $0.272^{b}$ \\
\hline AMI & $1(7)$ & $0(0)$ & $0(0)$ & $1(7)$ & $0.557^{\mathrm{b}}$ \\
\hline POAF & $6(43)$ & $8(57)$ & $1(7)$ & $2(14)$ & $0.009^{\mathrm{b}}$ \\
\hline Infectious complications & $3(21)$ & $5(36)$ & $0(0)$ & $5(36)$ & $0.069^{b}$ \\
\hline
\end{tabular}

Data expressed as mean $\pm S D$, median (in parentheses) for continuous variable, or number (\%) for categorical variables

$P O N V$ postoperative nausea and vomiting, $M V$ mechanical ventilation, $P O$ postoperative, EVA encephalic vascular accident, $P O A F$ postoperative atrial fibrillation,

$A M I$ acute myocardial infarction

${ }^{a}$ Kruskal-Wallis test

${ }^{\mathrm{b}}$ Chi-square test 
from $\mathrm{CPB}$ or during ICU recovery, but also instances of POAF were significantly reduced. Apparently, sparing of vasoactive drugs is a function of oral $\mathrm{CHO}$ intake, whereas reduced rates of POAF are attributable to intraoperative infusion of $\omega-3$ PUFA. In addition, groups given $\mathrm{CHO}$-enriched drinks experienced fewer postoperative infections.

These results are in agreement with two previous studies that document speedy recovery and less need of vasoactive drugs, if oral $\mathrm{CHO}$ loading is done prior to cardiac surgery $[7,8]$. Curtailing of preoperative fasting, with $\mathrm{CHO}$ loading, is no longer a novelty approach [9]. This practice of abandoning prolonged fasts is safe and has been endorsed by anesthesiology societies around the world [10, 11]. CHO-enriched drinks may ameliorate postoperative insulin sensitivity, decrease episodes of PONV, and alleviate preoperative sensations of thirst and hunger [6]. In cardiac surgery, there is not much data on the benefits of this particular strategy, so the present findings are especially relevant. As anticipated, there were no instances of bronchial aspiration in the two groups given $\mathrm{CHO}$ loads, nor in the groups receiving only water.

The benefits of $\omega-3$ PUFA have been reported for decades in several areas of medicine, but primarily in the realms of cardiology and intensive care. Intravenous $\omega-3$ PUFA is rapidly incorporated by cell membranes [12] and may reduce the production of pro-inflammatory mediators (eg, prostaglandins, thromboxanes, leukotrienes, platelet-activating factor, and cytokines) $[13,14]$. Such effects have been credited for reduced hospital stays [15] and lower rates of severe infection [16] in critically ill patients, fewer postoperative complications [17], and possibly lower mortality in acute lung injury [18]. In the field of cardiology, other benefits include declines in morbidity and mortality from congestive heart failure and in sudden death from infarction [19]. The administering of $\omega-3$ PUFA is also linked with better control of dyslipidemia, heart rate, and chronic atrial fibrillation $[20,21]$. However, data in the literature are controversial, some studies failing to confirm these benefits [22].

A number of investigations have addressed the benefits of perioperative $\omega-3$ PUFA infusion, or even preoperative oral treatment, in the context of cardiovascular surgery. In a study by Berger et al. [1], two randomly assigned groups were compared, one a placebo (control) group. The other was given infusions of $\omega-3$ PUFA $(0.2 \mathrm{~g} / \mathrm{kg}) 12 \mathrm{~h}$ and $2 \mathrm{~h}$ preoperatively and immediately following surgery. A significant decline in postoperative IL-6 (cytokine) was found in the $\omega-3$ PUFA group, as well as a reduced incidence of arrhythmias, but without significant between-group differences. Our study showed a lower incidence of POAF, as reported in a meta-analysis by Langlois et al. [3]. Their efforts encompassed a systematic review of 19 randomized clinical trials, for a total of 4335 patients undergoing cardiac surgery. Similar to our study, this meta-analysis found no effect of $\omega-3$ PUFA on duration of ICU stays and postoperative mortality rate. However, this metaanalysis showed that infusion of $\omega-3$ PUFA was associated with shorter hospital stays and lower incidence of POAF, especially with use of CPB. The reductions of POAF seen in our patients and in the meta-analysis above perhaps reflect a dampening of inflammatory response in this setting, induced by intraoperative infusion of $\omega-3$ PUFA.

Outcomes of the present study must be interpreted with caution, because of the small number of patients included. Indeed, further studies on this issue are warranted. Nonetheless, we may conclude that perioperative use of these two nutrients seems beneficial for recovery of patients undergoing CABG.

\section{Abbreviations \\ CABG: Coronary artery bypass grafting; $\mathrm{CHO}$ : Carbohydrate; CPB: Cardiopulmonary bypass; ICU: Intensive care unit; POAF: Postoperative atrial fibrillation; PONV: Postoperative nausea and vomiting; $\omega-3$ PUFA: Omega-3 polyunsaturated fatty acids}

\section{Acknowledgments}

We thank the professionals of BioMed Proofreading LLC for English corrections and copyediting this manuscript.

\section{Funding}

CNPq (Conselho Nacional de Desenvolvimento Científico e Tecnológico "National Counsel of Technological and Scientific Development" of Brazil) has partially funded the study.

\section{Availability of data and materials}

The datasets used and/or analysed during the current study available from the corresponding author on reasonable request.

\section{Authors' contributions}

GRF conception and design of the study, acquisition of data, drafting the manuscript and agrees to be accountable for all aspects of the work in ensuring that questions related to the accuracy or integrity of any part of the work are appropriately investigated and resolved; PRLL, DCB, TCS \& LNB acquisition of data, and given final approval of the version to be published; LRT acquisition of data, randomization of the study, and given final approval of the version to be published; NJS Statistical analysis, and given final approval of the version to be published; JEA-N conception and design of the study, analysis and interpretation of data; drafting the manuscript and given final approval of the version to be published; agrees to be accountable for all aspects of the work in ensuring that questions related to the accuracy or integrity of any part of the work are appropriately investigated and resolved. All authors read and approved the final manuscript.

\section{Competing interests}

The authors declare that they have no competing interests.

\section{Consent for publication}

"Not applicable".

\section{Ethics approval and consent to participate}

The Ethics Committee of the General University Hospital, Cuiabá approved the study design (Protocol No 30493514.5.000.5165; 2014). The trail was registered at Clinical Trials (NCT: 03017001). All subjects have signed a consent form to participate of the study.

\section{Publisher's Note}

Springer Nature remains neutral with regard to jurisdictional claims in published maps and institutional affiliations. 


\section{Author details}

Federal University of Mato Grosso, Cuiabá, Brazil. ${ }^{2}$ General University Hospital, Cuiabá, Brazil. ${ }^{3}$ UNIC - University of Cuiabá, Cuiabá, Brazil. ${ }^{4}$ Cardiovascular Department, General University Hospital, Cuiabá, Brazil. ${ }^{5}$ Nutrition Service, General University Hospital, Cuiaba, Brazil. ${ }^{6}$ Department of Statistics, Federal University of Mato Grosso, Cuiabá, Brazil. ${ }^{7}$ Federal University of Mato Grosso and UNIVAG Medical School, Varzea Grande, Brazil. ${ }^{8}$ Rua Mal. Floriano Peixoto, 1520/503 - Duque de Caxias II, CEP:78045-395 Cuiabá, Brazil.

Received: 2 February 2017 Accepted: 11 April 2017

Published online: 20 April 2017

\section{References}

1. Berger MM, Delodder F, Liaudet L, Tozzi P, Schlaepfer J, Chiolero RL, et al. Three short perioperative infusions of n-3 PUFAs reduce systemic inflammation induced by cardiopulmonary bypass surgery: a randomized controlled trial. Am J Clin Nutr. 2013:97:246e54.

2. Albert CM, Campos H, Stampfer MJ, Ridker PM, Manson JE, Willett WC, et al. Blood levels of long-chain n-3 fatty acids and the risk of sudden death. $\mathrm{N}$ Engl J Med. 2002;346:1113-8.

3. Langlois PL, Hardy G, Manzanares W. Omega-3 polyunsaturated fatty acids in cardiac surgery patients: An updated systematic review and meta-analysis. Clin Nutr. 2016(16). doi: 10.1016/j.clnu.2016.05.013. [Epub ahead of print]

4. Yadava M, Hughey AB, Crawford TC. Postoperative Atrial fibrillation: incidence, mechanisms, and clinical correlates. Heart Fail Clin. 2016;12(2):299-308.

5. Perrier S, Meyer N, Hoang Minh T, Announe T, Bentz J, Billaud P, Mommerot A, Mazzucotelli JP, Kindo M. Predictors of Atrial fibrillation after coronary artery bypass grafting: a Bayesian analysis. Ann Thorac Surg. 2017;103(1):927. doi:10.1016/j.athoracsur.2016.05.115.

6. Pimenta GP, de Aguilar-Nascimento JE. Prolonged preoperative fasting in elective surgical patients: why should we reduce it? Nutr Clin Pract. 2014; 29(1):22-8.

7. Feguri GR, Lima PR, Lopes AM, Roledo A, Marchese M, Trevisan M, Ahmad $H$, Freitas BB, Aguilar-Nascimento JE. Clinical and metabolic results of fasting abbreviation with carbohydrates in coronary artery bypass graft surgery. Rev Bras Cir Cardiovasc. 2012;27(1):7-17.

8. Breuer JP, von Dossow V, von Heymann C, Griesbach M, von Schickfus M, Mackh E, Hacker C, Elgeti U, Konertz W, Wernecke KD, Spies CD. Preoperative oral carbohydrate administration to ASA III-IV patients undergoing elective cardiac surgery. Anesth Analg. 2006;103(5):1099-108.

9. Maltby JR. Fasting from midnight - the history behind the dogma. Best Pract Res Clin Anaesthesiol. 2006;20(3):363-78.

10. American Society of Anesthesiologists Committee. Practice guidelines for preoperative fasting and the use of pharmacologic agents to reduce the risk of pulmonary aspiration: application to healthy patients undergoing elective procedures: an updated report by the American society of anesthesiologists committee on standards and practice parameters. Anesthesiology. 2011;114(3):495-511.

11. Smith I, Kranke P, Murat I, Smith A, O'Sullivan G, Søreide E, Spies C, in't Veld B; European Society of Anaesthesiology. Perioperative fasting in adults and children: guidelines from the European Society of Anaesthesiology. Eur J Anaesthesiol. 2011;28(8):556-69.

12. Morlion BJ, Torwesten E, Lessire H, Sturm G, Peskar BM, Furst P, et al. The effect of parenteral fish oil on leukocyte membrane fatty acid composition and leukotriene-synthesizing capacity in patients with postoperative trauma. Metabolism. 1996:45:1208-13.

13. Mayer K, Fegbeutel C, Hattar K, Sibelius U, Kramer HJ, Heuer KU, et al. Omega-3 vs. omega-6 lipid emulsions exert differential influence on neutrophils in septic shock patients: impact on plasma fatty acids and lipid mediator generation. Intensive Care Med. 2003;29:1472-81.

14. Mayer K, Gokorsch S, Fegbeutel C, Hattar K, Rosseau S, Walmrath D, et al. Parenteral nutrition with fish oil modulates cytokine response in patients with sepsis. Am J Respir Crit Care Med. 2003;167:1321-8.

15. Pradelli L, Mayer K, Muscaritoli M, Heller AR. n-3 fatty acid-enriched parenteral nutrition regimens in elective surgical and ICU patients: a metaanalysis. Crit Care. 2012;16(5):R184.

16. Palmer AJ, Ho CK, Ajibola O, Avenell A. The role of $\omega-3$ fatty acid supplemented parenteral nutrition in critical illness in adults: a systematic review and metaanalysis. Crit Care Med. 2013;41(1):307-16.
17. Ma YJ, Liu L, Xiao J, Cao BW. Perioperative $\omega-3$ polyunsaturated fatty acid nutritional support in gastrointestinal cancer surgical patients: a systematic evaluation. Nutr Cancer. 2016;68(4):568-76.

18. Li C, Bo L, Liu W, Lu X, Jin F. Enteral immunomodulatory diet (omega-3 fatty acid, $y$-linolenic acid and antioxidant supplementation) for acute lung injury and acute respiratory distress syndrome: an updated systematic review and meta-analysis. Nutrients. 2015;7(7):5572-85.

19. Macchia A, Levantesi G, Franzosi MG, Geraci E, Maggioni AP, Marfisi R, Nicolosi G, Schweiger C, Tavazzi L, Tognoni G, Valagussa F, Marchioli R, GISSI-Prevenzione Investigators. Left ventricular systolic dysfunction, total mortality, and sudden death in patients with myocardial infarction treated with n-3 polyunsaturated fatty acids. Eur J Heart Fail. 2005;7(5):904-9.

20. Mozaffariam D, Geelen A, Brouwer I, Geleijnse JM, Zock PL. Effect of fish Oil on heart rate in humans. A meta-analysis of randomized controlled trials. Circulation. 2005;112:1945-52.

21. Eckel RH, Jakicic JM, Ard JD, de Jesus JM, et al. 2013 AHA/ACC guideline on lifestyle management to reduce cardiovascular risk: a report of the American college of cardiology/American heart association task force on practice guidelines. J Am Coll Cardiol. 2014;63:2960-84. PMID: 24239922.

22. Avanzini F, Franzosi MG, Geraci E, Giansiracusa N, Rocchetti L. Risk and prevention study collaborative group. $\mathrm{n}-3$ fatty acids in patients with multiple cardiovascular risk factors. N Engl J Med. 2013;368(19):1800-8.

\section{Submit your next manuscript to BioMed Central and we will help you at every step:}

- We accept pre-submission inquiries

- Our selector tool helps you to find the most relevant journal

- We provide round the clock customer support

- Convenient online submission

- Thorough peer review

- Inclusion in PubMed and all major indexing services

- Maximum visibility for your research

Submit your manuscript at www.biomedcentral.com/submit
) Biomed Central 